\title{
Oxidative stress in term small for gestational age neonates born to undernourished mothers: a case control study Piyush Gupta*1, Manish Narang1, BD Banerjee ${ }^{2}$ and Srikanta Basu ${ }^{3}$
}

Address: ${ }^{1}$ Department of Pediatrics, University College of Medical Sciences and Guru Tegh Bahadur Hospital, New Delhi 110 095, India, 2Department of Biochemistry, University College of Medical Sciences, New Delhi 110 095, India and 3 Department of Pediatrics, Government Medical College, Sector 32, Chandigarh, India

Email: Piyush Gupta* - drpiyush@satyam.net.in; Manish Narang - manishnarang_2710@yahoo.com; BD Banerjee - banerjeebd@hotmail.com; Srikanta Basu - srikantabasu@hotmail.com

* Corresponding author

Published: 20 July 2004

BMC Pediatrics 2004, 4:14 doi:10.1186/147|-243|-4-14
Received: 12 February 2004

Accepted: 20 July 2004

This article is available from: http://www.biomedcentral.com/I47I-243I/4//4

(C) 2004 Gupta et al; licensee BioMed Central Ltd. This is an Open Access article: verbatim copying and redistribution of this article are permitted in all media for any purpose, provided this notice is preserved along with the article's original URL.

\begin{abstract}
Background: The objective of this study was to assess the status of oxidative stress in term small for gestational age (SGA) newborn infants born to undernourished mothers by estimating levels of erythrocyte superoxide dismutase (SOD), catalase, reduced glutathione, and serum malondialdehyde (MDA) in cord blood and comparing them to healthy appropriate for gestational age (AGA) controls. This was done in a case control design at a tertiary level teaching hospital.

Methods: We included 20 singleton healthy SGA newborn infants born between 38-40 weeks to undernourished mothers with a) post-pregnancy weight $<50 \mathrm{~kg}$ or height $<145 \mathrm{~cm}$ AND b) hemoglobin $<8.0 \mathrm{~g} / \mathrm{dL}$ or serum albumin $<2.5 \mathrm{~g} / \mathrm{dL}$. An equal number of age and sex matched AGA newborn infants born to healthy mothers served as Controls. Mothers with other risk factors and newborns with complications during delivery or immediate newborn period were excluded. MDA, SOD, catalase and reduced glutathione were measured in the cord blood of all neonates and compared between the groups (unpaired $t$ test); levels were also correlated to maternal weight, height, hemoglobin, and albumin by both univariate (pearsonian correlation) and multivariate (multiple regression) analysis.
\end{abstract}

Results: The activity of MDA was increased $(5.33 \pm 0.72$ vs $2.55 \pm 0.22 \mathrm{nmol} / \mathrm{mL} ; P<0.000 \mathrm{I})$ while levels of superoxide dismutase $(493.6 \pm 54.9$ vs. $786.8 \pm 79.1 \mathrm{U} / \mathrm{g} \mathrm{Hb} ; P<0.000 \mathrm{I})$, catalase $(\mathrm{I} .48 \pm$ 0.24 vs. $2.3 \mathrm{I} \pm 0.20 \mathrm{U} / \mathrm{g} \mathrm{Hb} ; P<0.000 \mathrm{I})$ and reduced glutathione ( $2.84 \pm 0.37 \mathrm{vs} 6.42 \pm 0.23 \mathrm{Umol} /$ $\mathrm{g} \mathrm{Hb}, P<0.000 \mathrm{I}$ ) were decreased in term SGA born to undernourished mothers as compared to term AGA born to healthy mothers. On univariate analysis, all the markers of oxidative stress correlated significantly with maternal parameters $(P<0.005)$. On multivariate analysis, maternal albumin and hemoglobin accounted for maximum correlation with the markers of oxidative stress.

Conclusions: Intrauterine malnutrition is associated with significant oxidative stress in small for gestational age neonates born at term to malnourished mothers.

\section{Background}

Oxidative stress occurs as a consequence of imbalance between the formation of oxygen free radicals and inacti- vation of these species by antioxidant defense system [1]. Oxygen free radicals are incriminated in the causation of several neonatal diseases including bronchopulmonary 
dysplasia, retinopathy of prematurity, persistent ductus arteriosus, necrotizing enterocolitis, intracranial hemorrhage and hypoxic ischaemic encephalopathy [2-5]. The role of oxidative stress is also clear and well known in the pathogenesis of acquired malnutrition [6-8].

It is apparent that the intrauterine period of life is a very important period from a nutritional standpoint $[9,10]$. The normal fetal growth is a result of complex interaction among the three components of maternal-placental-fetal unit. Nutritional status of the mother is the most important maternal factor leading to intrauterine growth retardation [10]. Malnutrition involves deficiency of not only the macronutrients i.e. fats, proteins, carbohydrates but also results in subphysiological concentration of most micronutrients. Many antioxidant defense systems depend on micronutrients or are micronutrients themselves [11]. Proteins provide amino acids for synthesis of antioxidant defense enzymes, reduced glutathione (GSH) and albumin (as sacrificial antioxidant protein). Therefore, one would expect a gross derangement of the antioxidant defense mechanisms in malnutrition. Small for gestational age (SGA) babies born at term to undernourished mothers provide a unique opportunity to have an insight into the mechanism and implications of the fetal growth retardation, secondary to intrauterine malnutrition. No study is available on the role of oxidative stress in term neonates born out of intrauterine growth retardation as a consequence of maternal malnutrition.

The body on account of susceptibility to oxidative insult, is naturally provided with an efficient antioxidant system. A series of enzymes also act as scavenging systems including superoxide dismutase (SOD), catalase and glutathione peroxidase. These enzymes are the first line of defense against reactive oxygen species and are generally referred to as primary antioxidants. Lipid peroxidation products are measured as an index of oxygen free radical generation. Malondialdehyde (MDA) is one such product generated in the tissues by free radical injury. Measurement of MDA provides a sensitive index of the lipid peroxidation and oxidative stress [1].

The present study was conducted to assess the status of oxidative stress in SGA babies born to undernourished mothers by estimating the blood levels of (i) free radical scavenger enzymes (superoxide dismutase and catalase), (ii) free radical scavenger (reduced glutathione) and (iii) lipid peroxidation product (malondialdehyde). We started with the hypothesis that SGA neonates babies born at term to malnourished women have deficient antioxidant defense mechanism and increased oxidative damage; this would be reflected by decreased level of free radical scavengers and excess of lipid peroxidation products.

\section{Methods}

This study was conducted over a period of 1 year in the Departments of Pediatrics and Biochemistry at University College of Medical Sciences and Guru Tegh Bagadur Hospital, New Delhi, India. The study protocol was approved by the Institutional Ethical Committee, and an informed signed consent was obtained from the expectant mothers.

\section{Enrollment}

The Study group consisted of 20 consecutive singleton small for gestational age (birth weight $<10$ percentile for gestational age), term neonates, otherwise healthy and born between 38-40 weeks to severely malnourished mothers. Mothers were selected if they (i) weighed $<50 \mathrm{~kg}$ (post-pregnancy) and/or had a height of $<145 \mathrm{~cm}$, AND (ii) had a hemoglobin $<8 \mathrm{~g} / \mathrm{dL}$ and/or serum albumin $<$ $2.5 \mathrm{~g} / \mathrm{dL}$. These mothers were unbooked and reported to us in labor. The Control group included 20 age and sex matched healthy term neonates. These babies were appropriate for gestational age (weighing between $10^{\text {th }}$ and $90^{\text {th }}$ percentile) born to healthy mothers under regular antenatal care. These mothers had a hemoglobin $>10 \mathrm{~g} / \mathrm{dL}$, serum albumin $>3.5 \mathrm{~g} / \mathrm{dL}$, height $>150 \mathrm{~cm}$, and a prepregnancy weight of more than $50 \mathrm{~kg}$. Only those mothers having an uncomplicated antenatal and obstetric history, and known date of conception were included.

Women with an established medical risk factor for having reduced or excessive birth weight of the neonate such as, extremes of age ( $<18$ or $>44$ years), hypertension, toxemia of pregnancy, renal disease, heart disease, diabetes, urinary tract infection, metabolic disorder, tuberculosis, smoking, and alcohol or chronic drug intake were excluded from both the groups. Infants were excluded if they had history of difficult delivery, fetal distress, one minute apgar score less than 8, congenital malformations, birth injury or any complication requiring special care e.g. sepsis, seizure, respiratory distress, congenital heart disease, hypothermia, hypoglycemia and hyperbilirubinemia etc. Infants born to mothers who received sedatives / anesthesia within 4 hours prior to delivery were also excluded. All included newborns were delivered by vaginal route, with vertex presentation.

Gestational age was assessed from the date of last menstrual period and concurrent clinical assessment using the New Ballard Score [12]. For classifying infants as appropriate or small for gestation, reference of weight was made to Lubchenko's charts of intrauterine growth [13]. Weight, length and circumferences of the mid-arm, head and chest were recorded for all neonates by the standard techniques within half an hour of birth. Ponderal index was calculated as weight $(\mathrm{g}) /[\text { length }(\mathrm{cm})]^{3} \times 100$. 


\section{Markers of oxidative stress}

Four mL of heparinized venous blood sample was collected from the umbilical cord just after delivery of the neonate and processed for the isolation of erythrocytes and plasma. The red cells were stored at $4{ }^{\circ} \mathrm{C}$ and all serum samples at $-20^{\circ} \mathrm{C}$ until analysis. The red cell samples were processed within 12 hours. Serum malondialdehyde (MDA) was measured using the colorimetric method described by Satoh [14], based upon the reaction of thiobarbituric acid (TBA) with MDA, one of the aldehyde products of lipid peroxidation. The absorbance of the MDA-TBA adduct thus produced was measured at $532 \mathrm{~nm}$ wavelength using a spectrophotometer. The activity of superoxide dismutase (SOD) in erythrocytes was determined by the method described by Marklund and Marklund [15] as modified by Nandi and Chatterjee [16], which is based on the inhibition of pyrogallol autoxidation brought about by SOD. The catalase activity of the erythrocytes was determined by the method of Sinha [17], based on the principle that dichromate in acetic acid is reduced to chromic acetate when heated in the presence of $\mathrm{H}_{2} \mathrm{O}_{2}$ with the formation of perchromic acid as an unstable intermediate. Reduced glutathione (GSH) was estimated by a method based on the development of yellow color with 5, 5' dithiobis-2-nitrobenzoic acid (DTB), which was measured at 432 um using a spectrophotometer [18].

\section{Statistical analysis}

One-sample Kolmagorov-Smirnov test was done to confirm the assumption of normality in the two groups for four outcome variables i.e., MDA, catalase, superoxide dismutase and reduced glutathione. The levels of MDA, catalase, superoxide dismutase and reduced glutathione were compared between the Study and Control group by unpaired $t$ test. The observed values for these four parameters of oxidative stress were correlated to the maternal anthropometry (weight, height, body mass index), hemoglobin and albumin; and the neonatal anthropometry (weight, length, head circumference, chest circumference, mid-arm circumference, ponderal index) by univariate analysis. For univariate analysis, Pearsonian correlation coefficient $r$ was calculated. Multivariate analysis was carried out by multiple regression analysis using stepwise selection method. While levels of MDA, catalase, superoxide dismutase and reduced glutathione were taken as dependent variables, the independent variables that were considered simultaneously with each of the dependent variable included maternal weight, height, body mass index, hemoglobin and albumin. Significance of correlation was calculated by the analysis of variance and F test. $P<0.05$ was considered significant. This level was also used as the cut-off for inclusion/exclusion in the stepwise selection method. The statistical analysis was carried out using SPSS version $10^{+}$at the Division of Biostatistics and Medical Informatics at our Institution.

\section{Results}

A total of 40 neonates, 20 each in the Study and Control groups were evaluated. Neonates in the two groups were intentionally matched for gestational age (median: 39 weeks; range 38-40 weeks) and sex (M:F::1:1). It is evident that the maternal parameters were significantly different between the two groups, by virtue of selection criteria (Table 1). The mean difference between the two groups in maternal weight and height was $12 \mathrm{~kg}$ and $9 \mathrm{~cm}$ respectively; mean hemoglobin and serum albumin differed by $3.6 \mathrm{~g} / \mathrm{dL}$ and $1.2 \mathrm{~g} / \mathrm{dL}$ respectively between the groups. The mean difference in neonatal weight between the groups was 765 grams (95\% CI: 617-913 grams). All the newborns in Study group were low birth weight $(<2.5$ $\mathrm{kg}$ ) as compared to the Controls in which no baby weighed below 2500 grams. Though there was a significant difference in the length of two groups (mean difference $2.5 \mathrm{~cm}, 95 \% \mathrm{CI}: 1.8-2.3 \mathrm{~cm}$ ), yet the length of all the babies in both the groups was within normative range. The head circumference ranged between $30-35 \mathrm{~cm}$ (median 34.1) in the SGA babies as compared to 34-36 $\mathrm{cm}$ (median $35.2 \mathrm{~cm}$ ) in the Control group; all values were within normative range. Most of infants in the study group had a Ponderal index (PI) $\leq 2$ (median, 1.9) as compared to the Control group where the PI was $>2$ in most of the cases (median, 2.22).

The biochemical markers of oxidative stress were distributed in a Gaussian fashion in the two groups. The levels of MDA were found to be significantly higher whereas those of superoxide dismutase, catalase, and reduced glutathione were significantly lower in the SGA newborns as compared to the AGA controls $(P<0.0001)$ (Table 2$)$.

Univariate analysis revealed significant correlation $(P<$ 0.001 ) between the markers of oxidative stress with maternal anthropometry, hemoglobin and albumin; and neonatal anthropometry (Table 3). Superoxide dismutase, catalase, and reduced glutathione correlated positively, while MDA had a negative correlation with all the neonatal and maternal parameters. Maternal albumin and neonatal weight appeared to be the most important parameters reflecting on the level of oxidative stress in the univariate analysis. A simple linear correlation was also found to exist between the products of lipid peroxidation (MDA), free radical scavenger enzymes (superoxide dismutase and catalase) and free radical scavengers (reduced glutathione); all these correlation were highly significant $(P<0.0001)$.

In the stepwise regression analysis for MDA, maternal albumin was found to be the most important predictor of 
Table I: Maternal and neonatal characteristics in the two groups

\begin{tabular}{lcc}
\hline Parameters & Study Group $(N=20)$ Mean \pm S.D & Control Group $(N=20)$ Mean \pm S.D* \\
\hline Maternal & & $156.1 \pm 3.3$ \\
Height $(\mathrm{cm})$ & $147.3 \pm 3.6$ & $56.8 \pm 3.9$ \\
Weight $(\mathrm{kg})$ & $44.7 \pm 5.5$ & $11.6 \pm 0.6$ \\
Hemoglobin $(\mathrm{g} / \mathrm{dL})$ & $8.0 \pm 0.9$ & $3.7 \pm 0.2$ \\
Serum albumin $(\mathrm{g} / \mathrm{dL})$ & $2.5 \pm 0.3$ & \\
Neonatal & & $2862 \pm 290$ \\
Weight $(\mathrm{g})$ & $2097 \pm 145$ & $50.1 \pm 1.4$ \\
Length $(\mathrm{cm})$ & $48.0 \pm 0.7$ & $11.0 \pm 0.3$ \\
Midarm circumference $(\mathrm{cm})$ & $9.5 \pm 0.5$ & $35.0 \pm 0.5$ \\
Head circumference $(\mathrm{cm})$ & $33.7 \pm 1.3$ & $31.9 \pm 0.4$ \\
Chest circumference $(\mathrm{cm})$ & $30.6 \pm 1.3$ & $2.2 \pm 0.2$ \\
Ponderal index & $1.9 \pm 0.1$ &
\end{tabular}

* All differences between the study and control group were highly significant $(P<0.0001)$

Table 2: Biochemical markers of oxidative stress in enrolled newborns

\begin{tabular}{|c|c|c|c|c|c|c|c|c|c|c|c|}
\hline \multirow[t]{2}{*}{ S. No. } & \multirow{2}{*}{$\begin{array}{l}\text { Biochemical } \\
\text { Markers }\end{array}$} & \multicolumn{4}{|c|}{ Study Group $(n=20)$} & \multicolumn{4}{|c|}{ Control Group $(n=20)$} & \multirow{2}{*}{$\begin{array}{c}P \text { - } \\
\text { value* }\end{array}$} & \multirow{2}{*}{$\begin{array}{c}\text { Mean difference } \\
(95 \% \mathrm{Cl})\end{array}$} \\
\hline & & $\begin{array}{l}\text { Mean } \\
\text { (SD) }\end{array}$ & SE & Median & Range & $\begin{array}{l}\text { Mean } \\
\text { (SD) }\end{array}$ & SE & Median & Range & & \\
\hline I. & $\begin{array}{l}\text { Malondialdehyde } \\
(\mathrm{nmol} / \mathrm{mL})\end{array}$ & $\begin{array}{l}5.33 \\
(0.72)\end{array}$ & 0.16 & 5.23 & $4.21-6.37$ & $\begin{array}{l}2.55 \\
(0.22)\end{array}$ & 0.05 & 2.51 & $2.12-2.92$ & $<0.0001$ & $\begin{array}{c}2.78 \\
(2.43,3.13)\end{array}$ \\
\hline 2. & $\begin{array}{l}\text { Superoxide } \\
\text { dismutase } \\
(\mathrm{U} / \mathrm{g} \mathrm{Hb})\end{array}$ & $\begin{array}{l}493.57 \\
(54.91)\end{array}$ & 12.28 & 493.53 & $402.4-583.5$ & $\begin{array}{l}786.81 \\
(79.05)\end{array}$ & 17.68 & 752.25 & $692.4-956.4$ & $<0.0001$ & $\begin{array}{c}-293.23 \\
(-336.80,-249.66)\end{array}$ \\
\hline 3. & $\begin{array}{l}\text { Catalase } \\
(\mathrm{U} / \mathrm{g} \mathrm{Hb})\end{array}$ & $\begin{array}{l}1.48 \\
(0.24)\end{array}$ & 0.05 & 1.45 & $1.09-2.02$ & $\begin{array}{l}2.31 \\
(0.20)\end{array}$ & 0.04 & 2.28 & $2.01-2.72$ & $<0.0001$ & $\begin{array}{c}-0.82 \\
(-0.97,-0.68)\end{array}$ \\
\hline 4. & $\begin{array}{l}\text { Reduced glutathione } \\
(\mu \mathrm{mol} / \mathrm{g} \mathrm{Hb})\end{array}$ & $\begin{array}{l}2.84 \\
(0.37)\end{array}$ & 0.08 & 2.85 & $2.3 I-3.4 I$ & $\begin{array}{l}6.42 \\
(0.23)\end{array}$ & 0.05 & 6.35 & $6.01-6.82$ & $<0.0001$ & $\begin{array}{c}-3.58 \\
(-3.78,-3.38)\end{array}$ \\
\hline
\end{tabular}

* Study group compared with the Control group by unpaired ' $t$ ' test.

lipid peroxidation in a multivariate set up $(r=-0.885$, SE $=0.171, F(1,38)=136.6, P<0.0001)$, followed by maternal hemoglobin $(r=0.925, \mathrm{SE}=0.586, F(2,37)=$ $109.577, P<0.0001)$. No other maternal parameter was able to enter the equation after the second step. Maternal albumin was also found to be the most important predictor for catalase $(r=0.810, \mathrm{SE}=0.279, F(1,38)=$ $72.31, P<0.0001)$ and reduced glutathione $(r=0.899$, SE $=0.82, F(1,38)=159.55, P<0.0001)$ in their respective multivariate models. Hemoglobin was the only other variable that contributed to prediction of catalase and reduced glutathione. For superoxide dismutase, maternal weight entered the equation on Step $1(r=0.834, \mathrm{SE}=$ 91.08, $F(1,38)=86.87, P<0.0001)$. Body mass index was included as the next important parameter $(r=0.904, \mathrm{SE}=$ $71.53, F(2,37)=82.72, P<0.0001)$. Two more variables entered the equation: i.e., albumin on Step $3(r=0.923$, $\mathrm{SE}=65.43, F(3,36)=68.66, P<0.0001)$, and height on
Step $4(r=0.933, \mathrm{SE}=61.83, F(4,35)=58.99, P<$ $0.0001)$. Hemoglobin did not add significantly to the prediction of superoxide dismutase in a multivariate set up $(P$ $=0.229)$.

\section{Discussion}

In this study, the oxygen free radical scavenging systems including superoxide dismutase, catalase, and reduced glutathione were lower (indicating deficient anti-oxidant defense mechanisms), and malondialdehyde (a measure of lipid peroxidation and oxidative damage) was higher in the cord blood of SGA neonates born to malnourished mothers as compared to AGA infants born to well nourished women, thus confirming our working hypothesis.

It is emphasized that these results apply specifically to the RBCs. The depressed superoxide dismutase, catalase and reduced glutathione levels in the undernourished group's 
Table 3: Simple correlation of oxidative stress markers with maternal and neonatal characteristics $(n=40)$

\begin{tabular}{|c|c|c|c|c|c|c|c|c|}
\hline \multirow[t]{2}{*}{ Maternal Characteristics } & \multicolumn{2}{|c|}{ MDA (nmoles/mL) } & \multicolumn{2}{|c|}{ Catalase (U/g Hb) } & \multicolumn{2}{|c|}{$\begin{array}{c}\text { Superoxide dismutase } \\
(\mathrm{U} / \mathrm{g} \mathrm{Hb})\end{array}$} & \multicolumn{2}{|c|}{$\begin{array}{c}\text { Reduced glutathione } \\
(\mu \mathrm{mol} / \mathrm{g} \mathrm{Hb})\end{array}$} \\
\hline & $\boldsymbol{r}$ & $P$-value & $r$ & $P$-value & $\boldsymbol{r}$ & $P$-value & $\boldsymbol{r}$ & P-value \\
\hline Weight (kg) & -0.781 & $<0.0001$ & 0.670 & $<0.0001$ & 0.834 & $<0.0001$ & 0.754 & $<0.0001$ \\
\hline Height $(\mathrm{cm})$ & -0.687 & $<0.0001$ & 0.653 & $<0.0001$ & 0.788 & $<0.0001$ & 0.819 & $<0.0001$ \\
\hline $\mathrm{BMI}$ & -0.507 & $<0.005$ & 0.437 & $<0.005$ & 0.568 & $<0.0001$ & 0.448 & $<0.005$ \\
\hline Hemoglobin (g/dL) & -0.863 & $<0.0001$ & 0.799 & $<0.0001$ & 0.819 & $<0.0001$ & 0.896 & $<0.0001$ \\
\hline Albumin $(g / d L)$ & -0.885 & $<0.0001$ & 0.810 & $<0.0001$ & 0.822 & $<0.0001$ & 0.899 & $<0.0001$ \\
\hline \multicolumn{9}{|l|}{ Neonatal Characteristics } \\
\hline Weight $(g)$ & -0.785 & $<0.0001$ & 0.777 & $<0.0001$ & 0.849 & $<0.0001$ & 0.865 & $<0.0001$ \\
\hline Length $(\mathrm{cm})$ & -0.707 & $<0.0001$ & 0.721 & $<0.0001$ & 0.798 & $<0.0001$ & 0.751 & $<0.0001$ \\
\hline Head circumference $(\mathrm{cm})$ & -0.554 & $<0.0001$ & 0.463 & $<0.005$ & 0.540 & $<0.0001$ & 0.495 & $<0.005$ \\
\hline Chest circumference $(\mathrm{cm})$ & -0.572 & $<0.0001$ & 0.529 & $<0.0001$ & 0.581 & $<0.0001$ & 0.530 & $<0.0001$ \\
\hline Midarm circumference $(\mathrm{cm})$ & -0.837 & $<0.0001$ & 0.772 & $<0.0001$ & 0.767 & $<0.0001$ & 0.833 & $<0.0001$ \\
\hline Ponderal index & -0.654 & $<0.0001$ & 0.627 & $<0.0001$ & 0.669 & $<0.0001$ & 0.747 & $<0.0001$ \\
\hline
\end{tabular}

RBCs can not be assumed to indicate a similar depression in enzymatic/non-enzymatic antioxidant protectants in other tissues, particularly the lungs. This is important because the lung, unlike RBCs has the ability to increase the production of key protective antioxidants when challenged by increased oxidative stress. Similarly, increased serum MDA values could well represent increased serum levels derived mainly or solely from unprotected RBCs alone.

The inclusion criterion in the present study were made stringent so as to exclude most factors other than the maternal malnutrition, which could have a bearing on the etiology of oxidative stress of the neonates. Only term neonates with an uneventful perinatal period were included. The cut off points for maternal height and weight clearly indicated that the included mothers had suffered chronic malnutrition, which was further supported by low hemoglobin and/or serum albumin levels. Infants delivered to these mothers had a ponderal index of $<2$ indicating that the growth retardation was predominantly asymmetrical and had occurred due to intrauterine nutritional deprivation during the late second and third trimester. An exact dietary history of the mother taken during pregnancy could have validated our point further. However, this was not possible due to our study design and logistic constraints.

A study of the profile of antioxidant defense potential of erythrocytes during the late fetal development revealed that erythrocyte catalase, glutathione peroxidase and plasma vitamin E levels correlated positively with increasing fetal weight [19]. In newborns, malnutrition may be a major element in the infant's intolerance against the harmful effects of free oxygen radicals [20]. A low birth weight infant is also frequently exposed to the conditions associated with increased generation of free oxygen radicals such as reperfusion and hypoxia [20]. Most of these data on LBW emanate from studies on preterms neonates $[19,21]$. It would be of interest to show that the degree of oxidative stress far outweighs the antioxidant defense mechanisms in SGA babies born as a result of maternal malnutrition.

SGA newborns had double the concentration of MDA as compared to AGA controls indicating significant oxidative damage. The activity of superoxide dismutase and reduced glutathione in the Study group was $60-65 \%$ and $44 \%$ of that in the normal healthy controls. Similar result was obtained with respect to catalase. Previous studies have also measured values of these enzymes in cord blood of term and preterm infants and the normative data is in accordance with our values in the Control group [19,22]. Maternal albumin and hemoglobin appeared to be the most important parameters to influence most of the markers of oxidative stress. This brings about an interesting hypothesis; biochemical indicators of nutrition are more closely linked to oxidative stress as compared to the anthropometric characteristics. On univariate analysis, neonatal mid-arm circumference was the most important determinant for MDA because MDA, a lipid peroxidation product is directly proportional to the amount of adipose tissue (generally measured by mid arm circumference).

However, the present study had certain limitations. While studying the role of antioxidants defenses in SGA babies born to undernourished mothers, total radical trapping capacity of anti-oxidants in plasma (TRAP) [23] should be 
studied and their levels compared to that in term AGA neonates. The concentrations of various other known antioxidants should also be measured and contribution of these antioxidants to TRAP should be calculated, which was not done in the present study. In order to understand the antioxidant defense system in the baby, a combined effect of the antioxidants should be measured, not just their individual cellular or plasma concentrations [24,25]. Determination of oxidized/reduced glutathione ratio [26] could have further validated our results.

Our study design did not permit estimation of markers of oxidative stress in AGA babies born to undernourished mothers and IUGR babies born to well nourished mothers. With the present study, it cannot be concluded whether SGA, maternal malnutrition or even both are the cause or effect of neonatal oxidative stress. The changes in oxidative stress markers could still be due only to IUGR and not to low dietary intake of mothers. Further studies are needed to translate this association into a cause-effect relationship.

\section{Conclusions}

This study proves that there is a strong evidence of oxidative stress in the SGA babies born to undernourished mothers as evidenced by increased lipid peroxidation and reduced free oxygen radical scavenger system. The erythrocyte protective mechanisms against oxidative damage are more efficient in AGA babies of healthy mothers. From the present study, it is difficult to infer whether the oxidative stress is a cause or effect of intrauterine growth retardation. If oxidative stress can be proven to be the cause of intrauterine growth retardation, antioxidant therapy may be considered as a prophylactic/therapeutic modality for preventing intrauterine growth retardation secondary to maternal malnutrition. Micronutrient supplementation to pregnant women, who are at higher risk of having fetal growth retardation, may alleviate oxidative stress and promote anti-oxidant defense mechanisms in their offspring. This may act as a catalyst in increasing their size at birth and decreasing subsequent neonatal morbidity and mortality [27], especially in the first week of life.

\section{Authors' contributions}

PG and BDB conceived and designed the study. MN collected data and performed biochemical tests under the supervision of BDB. PG and SB performed the statistical analysis. The article was drafted by SB and edited by PG. All authors read and approved the final manuscript.

\section{Competing interest}

None declared.

\section{References}

I. Rice-Evans C, Burdon R: Free radical lipid interactions and their pathological consequences. Prog Lipid Res 1993, 32:71-I I0.
2. Drury JA, Nycyk JA, Baines M, Cooke RW: Does total antioxidant status relate to outcome in very preterm infants? Clin Sci 1998, 94: |97-20I.

3. Lindeman JHN, Van Zoeren-Grobben D, Schrijver J, Speek AJ, Poorthuis BJHM, Berger HM: The total free radical activity of cord blood plasma in preterm and term babies. Pediatr Res 1989, 26:20-24.

4. Saugstad OD: Hypoxanthine as an indicator of hypoxia: its role in health and disease through free radical production. Pediatr Res 1988, 23: 143-150.

5. Sullivan JL: Iron, plasma antioxidants and the "oxygen radical disease of prematurity". Am J Dis Child I 988, I 42: | 341-I344.

6. Tatli MM, Vural H, Koc A, Kosecik M, Atas A: Altered antioxidant status and increased lipid peroxidation in marasmic children. Pediatr Int 2000, 42:289-292.

7. Ashour MN, Salem SI, El-Gadbon HM, Elwan NM, Basu TK: Antioxidant status in children with protein-energy malnutrition (PEM) living in Cairo, Egypt. Eur J Clin Nutr 1999, 53:669-673.

8. Sive AA, Subotzky EF, Malon $H$ : Red blood cell antioxidant enzyme concentrations in kwashiorkar and marasmus. Ann Trop Paediatr 1993, 13:33-38.

9. Swain S, Singh S, Bhatia BD, Pandey S, Krishna M: Maternal hemoglobin and serum albumin and fetal growth. Indian Pediatr 1994, 3 I:777-823.

10. Villar J, Belizan JM: The timing factor in the pathophysiology of the IUGR syndrome. Obstet Gynecol 1982, 37:499-506.

II. Evans P, Halliwell B: Micronutrient: oxidants/antioxidant status. J Nutr 2001, 85(suppl 2):S67-S74.

12. Ballard JL, Khoury JC, Wedig K, Wang L, Filers-Walsman DL, Lipp R: New Ballard Score expanded to include extremely premature infants. J Pediatr 1991, I 19:417-423.

13. Lubchenko LO, Hausman C, Dressler M, Boyd E: Intrauterine growth as estimated from live born birth weight data at $\mathbf{2 4}$ to 42 weeks of gestation. Pediatrics 1963, 32:793-800.

14. Satoh K: Serum lipid peroxide in cerebrospinal disorder determined by a new colorimetric method. Clin Chim Acta 1978, 40:37-43.

15. Marklund S, Marklund G: Involvement of superoxide anion radical in the auto-oxidation of pyrogallol and a convenient assay of superoxide dismutase. Eur J Biochem 1974, 47:469-474.

16. Nandi A, Chatterjee IB: Assay of superoxide dismutase activity in animal tissue. J Biosci 1988, I 3:305-315.

17. Sinha AK: Colorimetric assay of catalase. Anal Biochem 1972, 47:389-394.

18. Beutler E, Duran O, Kelly BM: Improved method for the determination of blood glutathione. J Lab Clin Med I 963, 5 I:882-888.

19. Huertas JR, Palomino N: Lipid peroxidation and antioxidants in erythrocyte membranes of full term and preterm newborns. Biofactors 1998, 8:133-137.

20. Frank L, Sosenko IRS: Failure of premature rabbits to increase antioxidant enzymes during hypertoxic exposure: increased susceptibility to pulmonary oxygen toxicity compared with term rabbits. Pediatr Res 1991, 29:292-296.

21. Saugstad OD: Oxygen toxicity in the neonatal period. Acta Paediatr Scand 1990, 79:881-892.

22. Yoshioka T, Kawada K, Shimada T, Mori M: Lipid peroxidation in maternal and cord blood and protective mechanism against activated oxygen toxicity in the blood. Am J Obstet Gynecol I979, I35:372-376.

23. Lindeman JHN, Zoeren-Grobben DV, Schrijiver J, Speek AJ, Poorthuis $\mathrm{BJHM}$, Berger HM: The total free radical trapping ability of cord blood plasma in preterm and term babies. Pediatr Res 1989, 26:20-24.

24. Willson RL: Free radical protection: why vitamin E, not vitamin C, beta carotene or glutathione? In: Biology of Vitamin E. Ciba Foundation Symposium I 0 I London: Pitmann Books; I 983:19-44.

25. Wayner DDM, Burton GW, Ingold KU, Barley DRC, Locke S: The relative contributions of vitamin $E$, urate, ascorbate and proteins to the total radical trapping antioxidant activity of human blood plasma. Biochem Biophys Acta 1987, 924:408-4I9.

26. Nemeth I, Boda D: Blood glutathione redox ratio as a parameter of oxidative stress in premature infants with IRDS. Free Rad Biol Med 1994, 16:347-353.

27. Hobbins J: Morphometry of fetal growth. Acta Paediatr 1997, Suppl 423: $165-168$. 


\section{Pre-publication history}

The pre-publication history for this paper can be accessed here:

http://www.biomedcentral.com/1471-2431/4/14/prepub

Publish with Bio Med Central and every scientist can read your work free of charge

"BioMed Central will be the most significant development for disseminating the results of biomedical research in our lifetime. " Sir Paul Nurse, Cancer Research UK

Your research papers will be:

- available free of charge to the entire biomedical community

- peer reviewed and published immediately upon acceptance

- cited in PubMed and archived on PubMed Central

- yours - you keep the copyright 